\title{
Autonomia Intelectual e Moral como Finalidade da Educação Contemporânea
}

Este trabalho representa um esforço reflexivo, no sentido de auxiliar os educadores na busca de parâmetros pedagógicos neste final de século.

Baseados nas premissas centrais da Psicologia Genética (Piaget), propomos uma revisão das práticas pedagógicas, que estão baseadas preferencialmente no Instrucionismo, tomando como referencial o Construtivismo.

A temática básica que perpassa todo este estudo fundamenta-se na noção piagetiana de autonomia, tanto no campo cognitivo como no campo afetivo, pois os dois năo podem ser dissociados, conforme o pensamento de Piaget.

Concluímos este estudo salientando que a recorrência às premissas da Psicologia Genética sobre o desenvolvimento da autonomia cognitiva e moral, redirecionará a educação rumo aos desafios e premências do século que se aproxima.

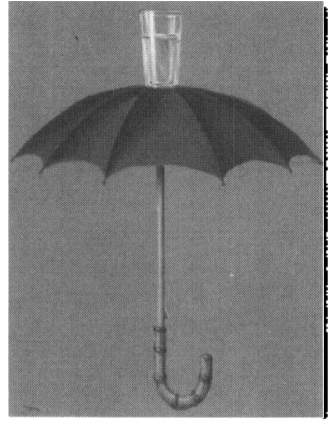

Jesus

Garcia Pascual

Protessor da untversickode Federoll do Cearó Gractuado em Filosofia. Psicologia e Peologogía Mestie em Psicologia Cilnico

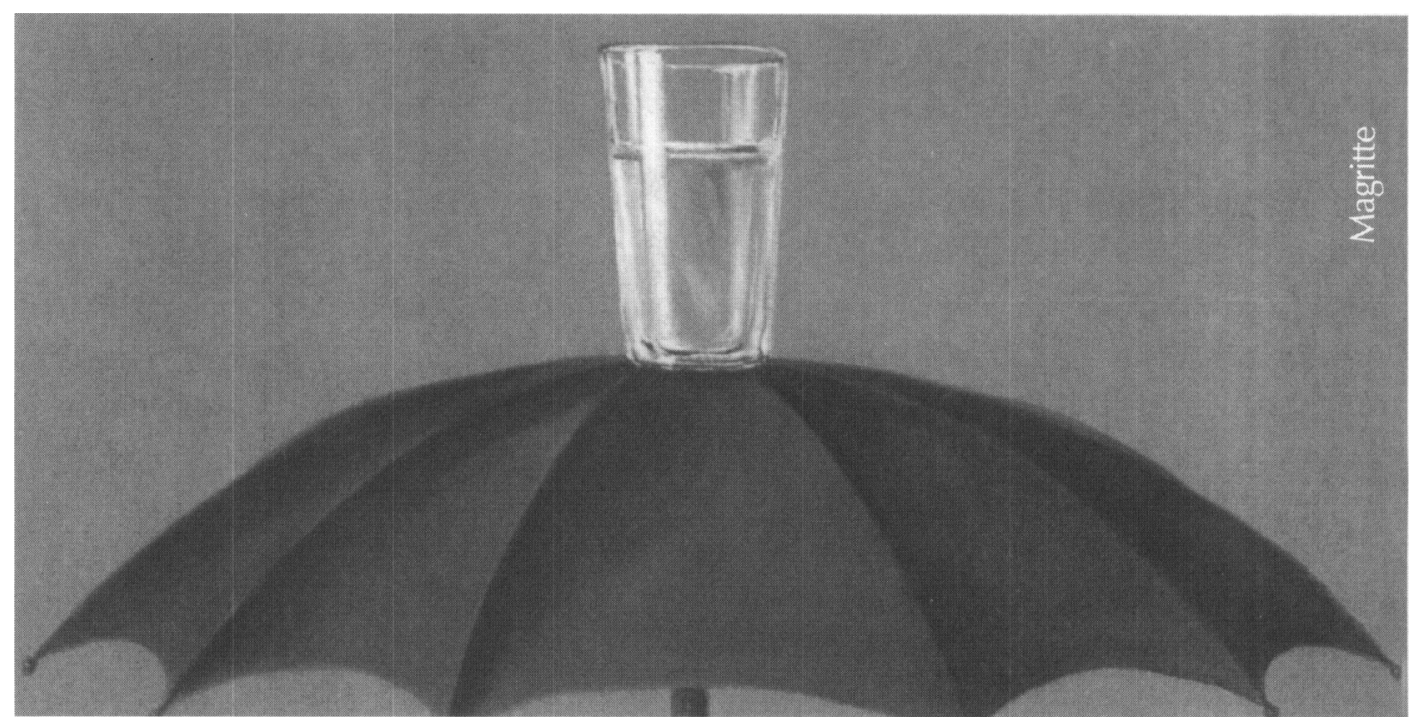

O tema que nos propomos a estudar - $A$ Autonomia intelectuale Moral como Finalidade da Educaçāo Contemporânea - exige, de imediato, a apresentação de alguns conceitos piagetianos, para que se possam extrair implicações construtivistas na educação de hoje. formularmos os conceitos de autonomia intelectual e moral, - que perpassam, de forma diluída, toda sua obra - mas que se concentram nas seguintes publicações: $O$ Juizo Moral na Criança; Lógica e Conhecimento Científico; Epistemologia Genética; Estudos Sociologicos; Seis Estudos de Psicologia; Sabedoria e llusões da Filosofia; Biologia e Conhecimento; o Estruturalismo. 
O Construtivismo vem se firmando entre nós como uma força cada vez mais pungente no campo da educaçăo contemporânea. Entretanto, esvazia-se-lhe muitas vezes dos seus componentes epistemológicos, apre-sentandoo apenas como mais um método pedagógico. Mas Jean Piaget buscou, prio-ritariamente, respostas para a questão crucial do conhecimento e suas decalages verticais e horizontais :

"Uma segunda aproximação do que seja epistemologia, pode ser entendida como [....Jo estudo da passagem de estados de menor conhecimento para estados de um conhecimento mais fundamentados". (Piaget, 1967:7).

Como se passa de um conhecimento de menor qualidade para outro de qualidade superior? Esta era a pergunta norteadora dos questionamentos epistemológicos piagetianos. Permanecer, entretanto, no campo filosóficoapriorismo ou empirismo - corria-se orisco de não sair da pura especulação. Daí que Piaget se autodenomina "um ex-futuro-filósofo" (Piaget,1978). Deixou de ser algo que ele nunca foi!

Ele busca, pois, na psicologia o campo experimental, onde possa elaborar sua teoria construtivista sobre o conhecimento. Piaget defende, energicamente, que não há conhecimentos (conteúdos) inatos nem estruturas preformadas no sujeito cognoscente - postura anti-apriorista -; mas também, afirma Piaget, a experiência por si só não fornece ao sujeito conhecimentos da ordem lógicomatemática (postura anti-empirista). Os conhecimentos sāo construídos através da ação do sujeito cognoscente com o meio e não apenas através do conceito ou da per-cepção, como defendiam o apriorismo ou o empirismo, respectivamente.

Restringir-nos-emos neste estudo a pinçar alguns conceitos básicos da obra piagetiana, no sentido de recortar melhor a noção de autonomia, conceito central deste trabalho. Para entender o que Piaget quer dizer quando se refere à noção de autonomia, - embora esse conceito apareça no opus piagetianum, originariamente, num contexto de moralidade (1932)-, pensamos que seja necessário recorrer ao modelo lógico-matemático para encontrar toda sua fecundidade conceptual.

\section{Autonomia Intelectual}

A autonomia intelectual caracteriza-se, na obra piagetiana, pela articulação de três conceitos axiais, que são: estrutura, gênese e equiibração.

\section{Estrutura}

Uma característica que a inteligência humana possui, segundo Piaget, se refere ao modelo de estrutura que a representa. Mas, ele recorre a um conceito de estrutura que supere os aspectos preformistas e predeterministas das estruturas cognitivas, defendidos pela Gestalt, como podemos observar neste pensamento do próprio Piaget :

"Uma estrutura é um sistema de transformação que comporta leis enquanto sistema (por oposição às propriedades dos elementos) e que se conserva e se enriquece pelo próprio jogo de suas transformaçōes, semque estas ultrapassem suas fronteiras ou recorram a elementos exteriores"

(Piaget, 1970:7).

Após um longo itinerário pelos campos da linguagem(1923) e da moralidade(1932), Piaget concentra-se no modelo lógico matemático, e a partir da década de cinqüenta, reconhece ser o melhor paradigma hipotético para compreender a inteligência humana como estrutura, estruturada e estruturante. Estudar a evolução da inteligência humana significa para Piaget, antes de mais nada, acompanhar suas transformações estruturadas e estruturantes da realidade, como acontece nas estruturas matemáticas. As operaçōes matemáticas $\mathrm{A}+$ $B=C ; B=C-A$ pertencem a uma mesma estrutura, pois a segunda vinculação entre os elementos $A, B, C(B=C-A)$ decorre da primeira ligação dos mesmos $(A+B=C)$.

As transformaçôes estruturais da inteligência humana assemelham-se a modelos lógicos (agrupamento) e a modelos matemáticos (grupo e reticulado). O próprio Piaget afirma que é possivel encontrar um isomorfismo entre as estruturas matemáticas, conhecidas como Grupo de Klein e o reticulado de Bourbaki e as estruturaçōes da inteligência no seu nível mais elevado, o nível formal. As trans- 
formaçōes que acontecem dentro da estrutura vâo se tornando cada vez mais vinculadas, segundo a lei da totalidade, atingindo sua forma máxima na estrutura de grupo, como mostraremos a seguir.

O grupo de quatro transformaçōes integra, numa mesma estrutura, as operaçóes de identidade ( $\mathbf{(})$, sua negativa $(\mathbf{N})$, a recíproca da idêntica ( $(R)$ e uma quarta operação, que é a recíproca da inversa (C), correlativa. Um exemplo poderá esclarecer melhor o formalismo deste parágrafo. Podemos encontrar na inteligência do adolescente as quatro operaçóes acima descritas quando ele realiza o seguinte curso de raciocínio diante desta proposiçăo: Os corpos leves flutuam (I). A essa operação de identidade chamaremos de $p$ (leves) que implica flutuar q. Então poderemos transcrever essa proposição da seguinte maneira : p . q (leveza implica em flutuaçāo). Mas, para que essa proposição seja verdadeira, torna-se necessário que não se confirme a operação inversa ou negativa $(\mathbf{N})$, isto é, que haja corpos leves que năo flutuem (ex.: uma agulha), que transcreveremos por p. q. Também é necessário confirmar ao mesmo tempo que todos os corpos que flutuam são leves (R), isto é, a recíproca da $\mathbf{I}$, que transcreveremos da seguinte forma $q$ . p (flutuar implica em ser leve). E finalmente, que não se possa dar que haja corpos não leves (pesados) que flutuem, $\sim$ p.q(recíproca da inversa $\mathbf{p .} \sim \mathbf{q}$ ).

Mas para atingir esse nivel de desenvolvimento estrutural, Piaget nos mostra, através da sua extensa obra sobre a construçāo das estruturas lógicas elementares, que a inteligência se estrutura ( e conseqüentemente, estrutura também a realidade) em esquemas menos elaborados, tais como os esquemas sensoriomotores, simbólicos e operatórios concretos.

\section{Gênese}

Uma outra característica que identifica a inteligência humana, segundo Piaget, diz respeito ao desenvolvimento das estruturas. A psicologia piagetiana é conhecida como genética porque coloca na gênese o princípio ativo da transformação dos conhecimentos. As teorias psicológicas do início do século XX não forneciam a Piaget o paradigma teórico capaz de fundamentar sua concepção de desenvolvimento cognitivo, pois, ou se recorria às teorias preformistas (estruturas sem gênese) ou ao ambientalismo(gênese sem estrutura). Piaget formula uma nova concepçăo entre esses dois conceitos, quando afirma :

"Não existe, na verdade, um ponto de gênese sem estrutura, pois toda gênese consiste na transformaçāo progressiva de uma estrutura anterior sob a influência de situaçōes novas, e toda gênese se transforma na construção de uma nova estrutura, de tal forma que toda gênese, mesmo se ela começa e se desenvolve sob o signo de desequilibrios parciais, consiste,

cedo ou tarde, numa restruturação de uma forma de equilibrio correspondente a esta nova estrutura"( Piaget, 1967:130-131).

Para Piaget nāo há conhecimentos inatos como se depreende do texto acima- que apenas precisam da experiência para aparecer na mente do sujeito, como querem os aprioristas. Mas também a experiência por si só não fornece conhecimentos lógicos ou matemáticos (ex.: relação entre todos e alguns), como decorre das posturas do empirismo. Piaget afirma que essas duas posturas epistemológicas partem de um princípio falso, quando afirmam que existem desde o início um sujeito cognoscente e um objeto capaz de ser conhecido.

"Por outro lado, e por conseqüência, se não existe no começo nem sujeito, no sentido epistêmico do termo, nem objetos concebidos como tais, nem, sobretudo, instrumentos invariantes de troca, o problema inicial do conhecimento será, portanto, o de construir tais mediadores..."(Piaget, 1970[1990]:8).

O processo psicogenético do desenvolvimento cognitivo, pois, seguirá seu caminho de adaptação através do processo da assimilação e da acomodaçã̃o; construindo estruturas cada vez melhores e mais estáveis. A esse processo Piaget chama de equilibraçāo majorante, que passaremos a estudar. 


\section{Equilibração}

Quando Piaget fala que a inteligência é uma forma de adaptação equilibradora em relação ao meio onde o organismo se encontra, ele na verdade está se referindo não só ao tema do conhecimento, mas à própria Vida como um processo contínuo de equilibração majorante. A palavra majorante nada mais é do que um galicismo que traduz os diferentes niveis de equilíbrio que a inteligência alcança através de seus processos adaptativos com o meio, na evolução da vida. A equilibração da inteligência aparece segundo três formas básicas de adaptação :

\section{a) os ritmos}

São repertórios que promovem repetiçōes no nível biológico ( ritmo cardíaco, respiratório etc.) ou no nivel intelectual (esquemas de assimilação reprodutora, generalizadora ou recognitiva). Todo objeto colocado ao alcance do bebê após o primeiro mês, será assimilado através do esquema de preensâol assimilação generalizadora).

\section{b) as regulações}

Sua função consiste em ....: "sincronizar as diferentes açōes rítmicas para conseguir sistematizar num conjunto os movimentos que, mantidos justamente num esquema estável, podem garantir, por exemplo, a conservação dos objetos através de suas transformaçōes". (Pain, 1992:16). Quando uma criança de quatro ou cinco anos vê a bola de massa se transformar numa salsicha, ela acompanha o processo de transformação; porém, seu pensa-mento (figurativo) se detém ora na forma de bola, ora na forma de salsicha que a massa assume; o que irá permitir-lhe afirmar que uma tem mais ou menos massa do que a outra. $A$ regulação intervém no sentido de coordenar essas duas açōes, levando a criança, algum tempo depois, a compensar o comprimento da saisicha com altura da bola. É o início da operaçōes concretas.

\section{c) a reversibilidade}

Mas as regulações que coordenam as ações são inicialmente unidirecionais. A rever- sibilidade introduz a possibilidade de integrar duas açōes - contrárias ou recíprocas - dentro do mesmo esquema através de uma operação mental reversível.

Mas a equilibraçāo intelectual requerida para constituir uma verdadeira autonomia intelectual só se completa, no nosso entender, ao atingir o estágio operatório formal, como se depreende deste pensa-mento piagetiano :

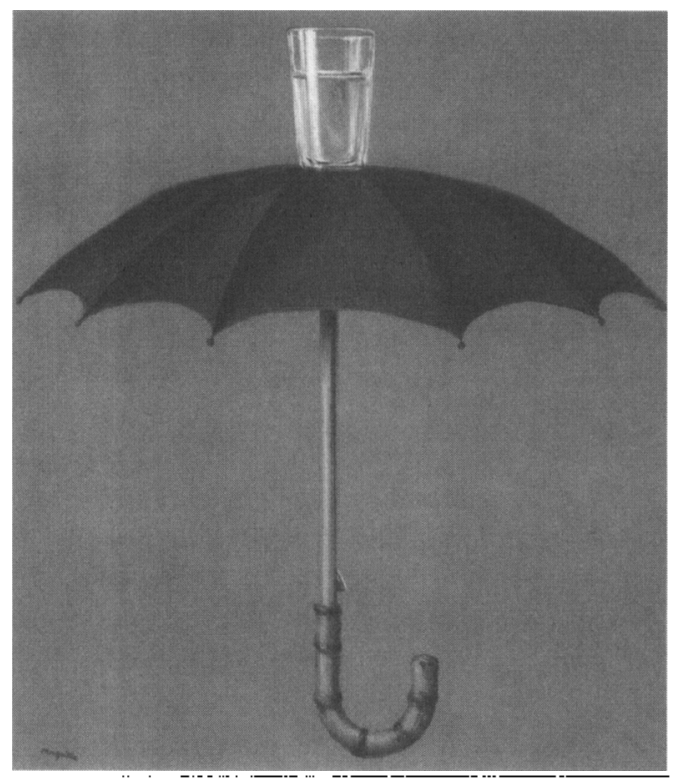

"Só depois que este pensamento formal começa, por volta dos 11 a 12 anos, é que se torna possivel a construção dos sistemas que caracteriza a adolescência. As operaçōes formais fornecem ao pensamento um novo poder, que consiste em destacá-lo do real, permitindo-the, assim, construir a seu modo reflexões e teorias.....Esta é uma das novidades essenciais que opõe a adolescência à infância: a livre atividade da reflexão espontânea" (Piaget, 1967 [1976]:64).

O processo de crescimento das possibilidades cognitivas - interação da assimilação com a acomodação, guiada pela auto-regulação- avoca os alunos na autonomia intelectual. Podemos descrever o aluno cognitivamente autônomo :

como sendo um sujeito curioso intelectualmente, que não se contenta com explicações decoradas.

Procura encontrar novas formas de resolver problemas do cotidiano. 
Pensa, preferencialmente, sobre proposiçōes e não apenas sobre a experiência fornecidas pelos objetos concretos.

Levanta hipóteses, pois a realidade pode ser pensada de forma diferente, a partir da compreensão dos possíveis. A realidade nada mais é do que uma das formas que os possiveis poderiam assumir.

O pensamento autônomo carrega dentro de si o que Piaget chamou de metafísica do adolescente, pois seu raciocínio privilegia o aspecto formal do pensamento, em detrimento da casuística. É no momento que o adolescente passa a raciocinar de modo formal, que temos os elementos necessários para falar sobre a autonomia intelectual.

Piaget não concebe $o$ desenvolvimento cognitivo desvinculado do afetivo. Sem sermos prolixos, recuireremos, apenas, a alguns momentos da sua obra onde ele o afirma de forma explícita.

".....estou persuadido que chegará o dia em que a psicologia das funçōes cognitivas e a psicanálise serão obrigadas a se fundir numa teoria geral que melhorará as duas corrigindo uma e outra, é esse futuro, que é conveniente prepararmos, mostrando desde agora as relações que podem existir entre as duas"(Piaget, 1972[1983]:226) e em outro texto :

\section{Ser outónomo moralmente significa poder analisar \\ crificamente a abrigotoriedode das normas.}

"Na medida em que a cooperaçāo entre os individuos coordena os pontos de vista em uma reciprocidade que assegura tanto a autonomia como a coesão, e na medida em que, paralelamente, o agrupamento das operaçōes intelectuais situa os diversos pontos de vista intuitivos em um conjunto reversivel, desprovido de contradições, a afetividade.[...] caracteriza-se pela aparição de novos sentimentos morais e, sobreutdo, por uma organizaçáo da vontade, que leva a uma melhor integração do eu e a uma regulação da vida afetiva".

(Piaget, 1967|1976):56). (grifos nossos).

\section{Autonomia Moral}

Constance Kamii, pedagoga nipo-suiça, que encontrou às margens do lago de Genebra seu referencial teórico se admira (1990), que o livro de Piaget "O Juf́zo Moral na Criança, escrito em 1932, tenha influenciado tão pouco o pensamento e as açōes dos educadores até hoje. Nesse livro, Piaget pesquisou o desenvolvimento da dimensão cognitiva da moralidade na criança; seu intuito não era estudar a prática (como as crianças agiam moralmente), mas o jutgamento que emitiam diante de certas situações fictícias. Trata-se, portanto, do aspecto racional das açōes morais.

Relendo a obra de Piaget no que concerne ao juízo moral, descobre-se que a autonomia moral implica em três características básicas, que passaremos a comentar.

Ser autônomo moralmente significa poder analisar criticamente a obrigatoriedade das normas. Interagindo com crianças pequenas, Piaget acompanhava a psicogênese da noção de obrigatoriedade moral. Ao afirmar que a obrigatoriedade moral segue uma gênese na criança, Piaget se opōe, conseqüentemente, ao imperativo categórico de Kant, para quem a obrigatoriedade da lei se constitui em categoria da Razão prática. E isso quer dizer que a noção de obrigatoriedade da moral kantiana nāo é psicogenética; basta esperar o momento (idade da razão) para que a criança compreenda o que deve fazer ou não deve fazer.

Piaget defende, entretanto, que o juízo moral não é inato; portanto, estará determinado pelos quatro fatores do desenvolvimento mental: maturaçāo, experiência, interação social e regulação. É aí que entra, no nosso entender, a participação da escola no processo da educaçāo moral dos seus alunos; pois na visão psicogenética não basta esperar, passivamente, que o aluno atinja, apenas pelo processo maturacional, o nivel da autonomia moral. Pois, após uma certa fase de anomia ( incompreensibilidade da obrigaçāo moral), determinar cronologicamente essa fase, requer uma contextualização social, histórica, cultural e educacional dos sujeitos -, a criança entende a obrigatoriedade de certos preceitos. Todavia, a obrigatoriedade decorre da autoridade do legislador; que geralmente, é representado numa figura proeminente do contexto familiar (pai, irmão mais velho) ou do contexto escolar (professor, colega mais velho). Esta figura, depositária da autoridade, se perde na história ancestral da humanidade, até se confundir com Deus. 
Agir moralmente correto, na fase que antecede à autonomia moral, significa obedecer $\mathrm{e}$ cumprir as ordens desse outrem superior. A lei é inquestionável; perante ela só cabe uma atitude moralmente correta: a obediência. Pelo fato de a relação entre os sujeitos estar baseada no respeito unilateral (adulto-criança) e pelo fato, também, de a lei provir de outrem, Piaget chama a essa fase de heteronomia moral, um helenismo composto de heteros(outro) e nomos (lei).

Heteronomia significa, pois, ser governado por outrem; enquanto que autonomia nos remete a ser governado por si próprio. Essa fase constitui um avanço significativo no desenvolvimento da moralidade, como no-lo diz o próprio Piaget :

" A heteronomia sucede a autonomia: a regra do jogo se apresenta à criança nāo mais como uma lei exterior, sagrada, enquanto imposta pelos adultos, mas como resultado de uma livre decisão, e como digna de respeito na medida em que é mutuamente consentida"

(Piaget, 1932[1994]:60)

Ser autônomo moralmente significa aceitar a responsabilidade subjetiva.

Na medida em que ocorre a descentração, isto é, o sujeito sai do seu próprio ponto de vista para se colocar no ponto de vista do outro, ocorre uma transformação no respeito, que agora se torna mútuo. Ser governado por si mesmo, todavia, não significa a preponderância do ponto de vista pessoal, o que levaria a autonomia a um juízo moral egocêntrico; ser autônomo moralmente perante a lei ou as normas escolares quer dizer poder entendê-las como sendo o resultado de acordos entre os diversos pontos de vista dos membros que compōem um grupo e não mais como algo imutável, que transcende a vontade e o raciocínio do mesmo.

Nesse sentido, Menezes (1975), na sua tese de doutorado, nos lembra uma hipótese teórica em que Piaget propōe um paralelismo entre o desenvolvimento das operaçōes intelectuais e o desenvolvimento social. Isso significa que autonomia moral, cooperação interpessoal e operaçōes cognitivas estão intrinsecamente unidas no pensamento piagetiano.
Os alunos, moraimente autônomos, compreendem que as normas escolares se tornam obrigatórias a partir do momento em que elas resumem acordos entre os parti-cipantes. É por isso que muitas vezes se torna tão difícil aplicálas quando eles (alunos) não participam da sua coníeç̧ão!

Ser autônomo moralmente significa, também, aceitar a responsabilidade subjetiva. A segunda característica que o juízo do aluno deve apresentar para que a moralidade possa ser considerada autônoma diz respeito à noção de responsabilidade. Atrelada à moralidade de heteronomia, Piaget encontra uma responsabilidade objetiva, imanente à própria ação, que năo leva em conta a intencio-nalidade do sujeito que age. Isso é estudado por Piaget em várias situaçōes-problema, que propunha às crianças pequenas, tais como: uma criança, desejando ajudar sua mãe na cozinha, foi lavar os pratos que estavam sobre a pia; como ela era baixinha e a pitha de pratos era alta, quebrou vários. Uma outra criança, desejando pegar um prato com doce em cima do armário, quebrou-o .

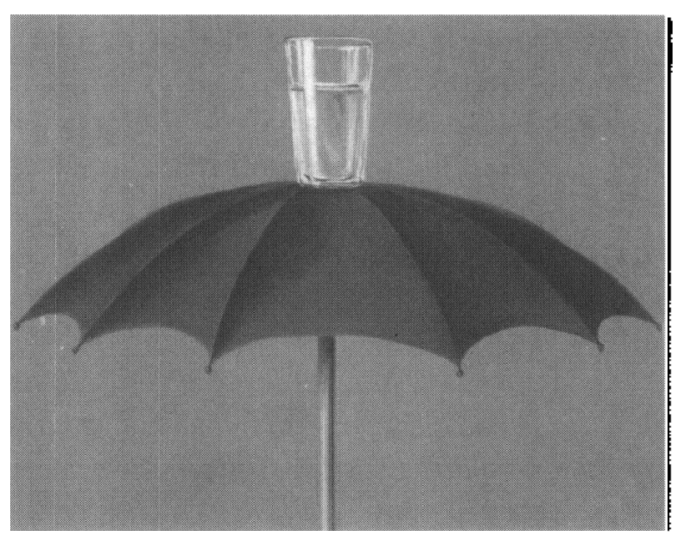

O juizo de culpabilidade, na fase de heteronomia, pende para a criança que quebrou mais pratos; independentemente da intenção que moveu a ação do sujeito, pois a culpabilidade é proporcional ao valor monetário ou social e à quantidade de objetos quebrados. Será necessário atingir o estágio de moralidade autônoma, para que a criança leve em consideração a intencionalidade do sujeito ao agir. Ser responsável moralmente significa ser um sujeito autônomo, que decide livremente.
Ser outônomo moralmente significa aceitar a responsabiliobade subjetiva.

\author{
Ser autônomo \\ moralmente \\ significa, enfim, \\ compreendero \\ sentido da justiça \\ distributiva $e$ \\ eqülfotiva.
}


Ser autônomo moralmente significa, emfim, compreender o sentido da justiça distributiva e eqüitativa. Piaget volta-se para a noção mais racional das noçōes morais - a noção de justiça -, pois acha que ela não está tão contaminada pelo respeito unilateral, quanto as noçōes de regras, mentira, roubo etc. No estudo da justiça (1932) já aparece uma das noçŏes nodais do sistema piagetiano mais evoluído; referimo-nos à noção de regulaçăo.

As noções do justo ou do injusto, que se impõem à consciência infantil, ancoram-se na condiçăo imanente de equilibrio regulador, que caracteriza as relaçóes entre as pessoas. Quando se rompe este equilíbrio social, isto é, o equilíbrio entre as relaçōes pessoais, tronase necessário reconstruí-lo para que a justiça seja restabelecida. Como repor o equilíbrio nas relaçôes humanas? Piaget estuda a gênese das noçōes de justiça retributiva, distributiva $e$ eqüitativa, encontrando uma evoluçăo inversa, embora não excludente, entre as duas primeiras, no desenvolvimento moral da criança.

A justiça retributiva afirma que uma ação é injusta quando se pune um inocente, quando se recompensa um culpado ou quando não é dosada a proporçáo entre o mérito e a pena aplicada. Mas existe, afirma Piaget, outra forma de justiça que não se fixa na punição como modo de restabelecer o equilíbrio, mas na repartiçăo justa, isto é, igualitária entre as pessoas

"No campo da justiça retributiva, a noção de sançāo expiatória nāo é mais aceita com a mesma docilidade que anteriormente, e as únicas sanções consideradas realmente como legítimas são as que decorrem da reciprocidade. A crença na justiça imanente diminui muito, e o ato moral é procurado, por si proprio, independentemente da sanção. No que se refere à justiça distributiva, a igualdade prevalece sobre qualquer outra preocupação. Nos conflitos entre a sançāo e a igualdade, por princípio, a igualdade tem primazia. Dá-se o mesmo a fortiori nos conflitos com a autoridade. Enfim, nas relações entre crianças, o igualitarismo impōe-se progressivamente com a idadel....jvemos caracterizar pelo sentimento de eqüidade, eque

é apenas um desenvolvimento do igualitarismo no sentido da relatividade "(Piaget, 1932 [7994]:237).

O adolescente busca, pois, a igualdade nāo na identidade, isto é, distribuir o mesmo prêmio ou mesmo castigo para todos, de uma forma universal, mas, pelo contrário, busca-a nas circunstâncias e peculiaridades atenuantes de cada situação. E Piaget resume brilhantemente esse avanço na noçāo de justiça, que evolui da justiça imanente à ação até à eqüidade, quando afirma :

"Longe de levar ao privilégio, tal atitude (recompensar ou distribuir diferentemente de acordo com as circunstâncias) conduz a tornar a igualdade mais efetiva do que era antes (quando era a mesma para todos, independentemente das circunstâncias) (Piaget, 1932[1994]:238).

Transportando essas três características que delineiam a autonomia moral, para o campo educacional, pensamos que o aluno moralmente autônomo será aquele :

i Tenha uma postura crítica perante as normas da escola.

Deduza a obrigatoriedade das mesmas, não da influência ou do prestígio do legislador.

- Apoie a obrigatoriedade das normas no acordo mútuo estabelecido entre os membros do grupo que irá interagir.

! Deverá julgar a responsabilidade das ações pela intencionalidade do ator e não a própria açăo em si.

Será capaz de discernir igualitarismo de eqüidade.

Pretendemos terminar este trabalho sobre as contribuiçōes da Psicologia Genética na construção da autonomia intelectual e moral dos alunos, propondo algumas diretrizes para a ação educativa nos campos do processo ensino-aprendizagem e no comportamento.

\section{Desequilibração e Aprendizagem}

Nos poucos livros - dentre sua vasta obra- em que Piaget se volta expressamente para a educaçâo, deixa sua marca indelével da genialidade. Após criticar severamente os procedimentos usados para avaliar a aprendizagem: 
"Todo já foi dito a respeito do valor dos exames escolares, e no entanto essa verdadeira praga da educação em todos os niveis continua a viciar -as palavras não chegam a ter a violência necessária- o relacionamento normal entre professor e aluno, comprometendo em ambos a alegria do trabaiho e, freqüentemente confiança recíproca" (Piaget, 1974:52); ele diz:

"O principal objetivo da educaçảo é criar homens que sejam capazes de fazer coisas novas, não simplesmente repetir o que as outras geraçóes fizeram" (Piaget, 1970:53).

A funçāo do professor, na abordagem piagetiana, näo se identifica com a de um repassador de informaçōes. Cabe ao professor, através de perguntas, mostrar ao aluno que seus esquemas asssimiladores são insuficientes para atingir um equilíbrio permanente. Quando um aluno responde que um objeto flutusa por causa da leveza seu peso e o outro, afunda por ser pesado, o professor deverá dẹsestabilizar esse equilibrio momentâneo a que o aluno chegou, apresentando o seguinte fato: um navio flutua e um alfinete afunda. Entretanto, o peso do navio é muitas vezes superior ao do alfinete. Diante desse novo fato, o aluno terá que buscar um equilíbrio melhor e maior que o anterior (equilibraçăo majorante).

\section{Construçāo e Conhecimento}

Piaget, quando se refere ao aspecto construtivista de sua epistemologia, evita falar de descoberta ou de busca, pois ambos conceitos pressupōem que o objeto do conhecimento já está dado de antemão. Construir um conhecimento é, na verdade, reconstruí-lo a partir das estruturas cognitivas do sujeito em interaçào com o meio. Poderemos falar de verdadeira construção de um conhecimento, quando o sujeito muda sua interação com o meio (físico ou social) a partir desse conhecimento. Se não acontecer a mudança, o resultado da aprendizagem será apenas uma informação que ficará na cabeça do aluno até o dia da avaliação.

\section{O Possível e o Conhecimento}

A finalidade última da aprendizagem tende a colocar o possivel como realidade primeira do conhecimento. A característica mais marcante da estrutura operatório-formal consiste, precisamente, em antecipar o possivel ao real, ficando este reduzido a um possível que se concretizou. Esse é, na verdade, o problema central da epistemologia genética, como afirma o próprio Piaget em um de seus últimos escritos : Entretanto, o que nos interesa nos problemas do possivel nảo é seu aspecto dedutível, o que nos levaria simplesmente às questỏes de generalização já estudadas, mas sim o processo de formação das possibilidades, ou seja, a 'abertura' para os novos possíveis que o sujeito descobrirá por si mesmo [....] É esse de fato o problema central da epistemologia construtivista: o da construçāo ou criação do que existia apenas em estado virtual do possivel e que o sujeito deverá atualizar" (Piaget,[1976], em: Leite, 1992:51-52). Um exemplo poderá esclarecer melhor estes pensamentos piagetianos; a invariância numérica de um conjunto de elementos permanece apesar das ordenaçōes que se façam. Quando uma criança pequena brinca de ordenar objetos, ainda não

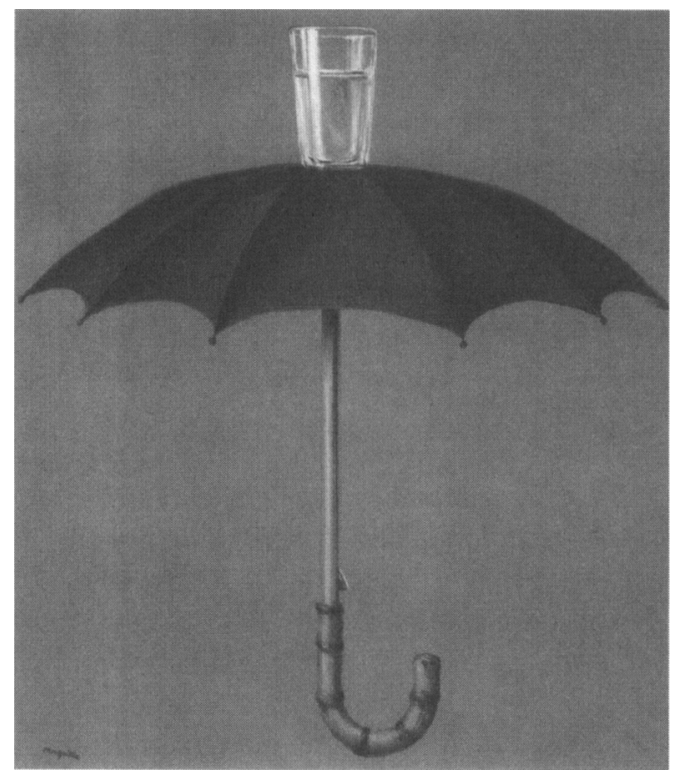

percebe que o número deles não muda, apesar das diversas formas de ordenaçào que faça (círculo, quadrado, estrela etc.). Mas só se tornará um possível atualizável quando é concebido ou compreendido pelo sujeito em suas condições de atualizaçào.

Cabe, pois ao professor facilitar modos diferentes de resolver os mesmos problemas ou situaçōes ( processo de acomodação); em 
vez de usar ao mesmos para resolver problemas diferentes (assimilaçāo generalizada). Desse modo o professor estará favorecendo a passagem da inteligência concreta - que lida com o real; para uma estrutura formal, que busca o possível como conteúdo de investigaçāo.

\section{A Indisciplina como Epocalidade nas Problemáticas Educacionais}

Um aspecto que enriquece a visão das interaçôes em sala de aula é fornecido pela dimensão genética que Piaget imprimiu tanto ao desenvolvimento cognitivo quanto ao moral. Isso significa que a participação dos alunos na elaboraçāo dos códigos normativos será sempre educativa, porém, de acordo com o grau de desenvolvimento daqueles.

Não será necessário esforçar-se muito para constatar que a indisciplina dos alunos (não trataremos aqui da violência) constitui uma problemática premente no campo educativo atual. Questionam-se os educadores sobre as práticas mais adequadas para normatizar o processo de ensino e aprendizagem. Abandonados os velhos métodos físicos do

"Caminhante, näo há cominho; faz-se caminho co andar; Ipoeta esparhol Antonlo Machado)

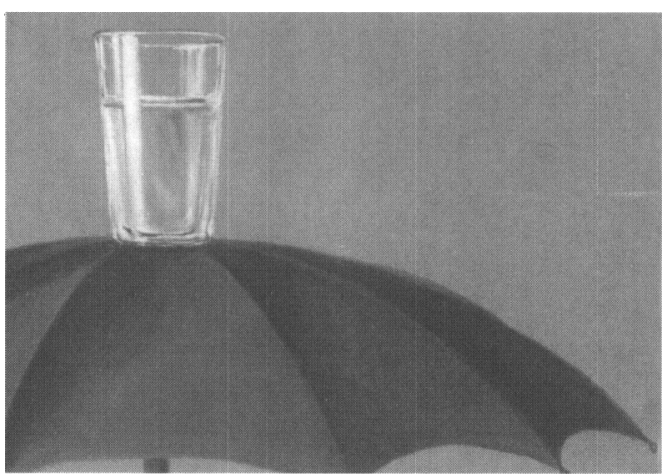

autoritarismo -que têm na palmatória seu símbolo, e, também, seu repúdio máximosos questionamentos oscilam entre castigos pedagógicos, passando pela persuasão até o espotaneísmo do Summerhill ou as teorias illichneanas da sociedade sem escolas.

A pergunta nodal que organiza as questōes sobre a indisciplina pode ser formulada da seguinte maneira : É possivel realizar o processo educacional na escola sem recorrer ao castigo ? essa pergunta, tanto no meio mais reacionário,

onde o castigo pertence intrinsecamente ao ato educativo; como no espontaneísmo pedagógico, para quem o castigo se torna um ato antipedagógico. Lançaremos mão do paradigma construtivista para iluminar esse assunto.

A noçāo de sanção está unida inerentemente à de justiça retributiva, que se define pela correlaçāo entre os atos e sua retribuição; que pode ser apenas expiatória ou (em nível mais evoluído) visar a reciprocidade. Piaget mos-trou, nas pesquisas entre crianças genebrinas, que 0 :

"...único meio de recolocar as coisas em ordem, através da sanção expiatória, é reconduzir o indivíduo à obediência, por meio de uma repreensão suficiente, e tornar sensivel a repreensão, acompanhando-a de um castigo doloroso"( Piaget, 1932[1994):161).

A sanção expiatória apresenta uma relação arbitrária entre a ação e o castigo.

No campo ainda da justiça retributiva, ele descobre uma forma mais evoluída de recompor o equilíbrio nas relaçōes interpessoais, chamada de sanção de reciprocidade. "Se a regra for violada, nāo há absolutamente necessidade, para recolocar as coisas em ordem, de uma repreensão dolorosa, que imponha, de fora, o respeito pela lei; basta que a ruptura do efo social, provocada pelo culpado, faça sentir seus efeitos; em outras palavras, basta pôra funcionara reciprocidade"

(Piaget 1932[1994]:162).

A conseqüência natural da sanção por reciprocidade - que na expiatória será sempre a dor do castigo- aqui se transforma numa desaprovação social, provocando constrangimento no infrator.

Pensamos, pois, que se torna necessária uma revisāo das práticas disciplinadoras na escola, que já olha para o próximo milênio. Para tanto, apresentaremos dois pontos, potencializadores de profícuo debate:

O primeiro ponto a ser salientado se refere à interação horizontal entre os próprios alunos como fonte privilegiada para a construção da 
autonomia moral. Como, então, deverá ser a mediação adulta, no caso a do professor, nas rupturas do elo social ? Certamente, uma mediação conciliadora entre os alunos não propiciará a construção de autonomia moral!

O segundo ponto diz respeito ao uso da sançāo por reciprocidade como meta da intervençăo no comportamento. A sançāo por reciprocidade constitui-se num recurso válido e desejável para ordenar o comportamento; entretanto, pode ser um obstáculo no desenvolvimento da moralidade autônoma, no que concerne à justiça eqüitativa, conforme o deduzimos deste texto piagetiano :

"Por volta dos onze-doze anos, finalmente, o igualitarismo da justiça distributiva é aperfeiçoado pela preocupaçāo com a eqüidade; aparece assim, no terceiro periodo, a justiça eqüitativa, que substitui o igualitaris-mo pela distribuição conforme as circuns-tâncias. Podemos observar o longo percurso que vai da justiça imanente até à justiça eqüitativa" (ibidem: 237).

Concluímos, pois, afirmando que as características da sociedade do próximo milênio demandam projetos pedagógicos avocados para o favorecimento da autonomia intelectual e moral, cujo paradigma teórico se encontra no Construtivismo. Finalizamos, parodiando o poeta espanhol Antonio Machado, "Caminhante, não há caminho; faz-se caminho ao andar; educador, nāo há receita pronta para a educaçāo; educa-se ao refletir e enfrentar os desafios da sociedade contemporânea.

Jesus Carcia Pacual Endereco: Rua Ildefonso Albuno, 2021 apto 301-Aldeota fortaleza /CE - CEP 601 15-000 Telefone: (10*485) 25.3.3197
Leite, B.L. (1992). Piaget e a Fscola de Cenebra. Sảo Paulo :Cortę,

Męnezes, E.D. B. de. (1975) Une Epistemologie des Sciences de I'homme: Aspects de la Contribution de Jean Piaget. Tese de doutoradomimeografada.

Pain, S. (1992) Psicometria genética. Sáo Paulo : Casa de Psicólogo.

Piaget, J.(1994) O Juizo moral na criança. Săo Paulo : Martins Fontes, [1932].
(1976). Seis Estudios de Psicologia. Rio de Janeio:Forense[1967].

(1967), Logique et conaissance scientifique. Paris:Gällimard,

(1970) . Epistennoiogia Cenética (1990) Sáo Paulo: Martins Fontes. (1970). Le Struturalisme. Paris:R:U.E,

(19701. Psicologia e Pedagogia, Rio de Janeiro:José Olympio.

(1970). Para onde vai a educação? Rio de janeiro:Forense

—(1972). Problemas de Psicologia Genética, Så Paulo: Abrikulitnal.

(1978). Sábedoria e liusóes dá filosofia. Sāo Paulo:Abril Cultural
Referências

bibliográficas 